- Technical Paper -

\title{
The Analysis of the Deposition Mechanism of Zn/Ni Alloy Plating Using an EQCM
}

\author{
Hidetaka HAYASHI $^{*}$ and Seiji MATSUDA
}

Faculty of Engineering, Okayama University (Tsushima-naka 3-1-1, Okayama 700-8530, JAPAN)

\author{
Received April 5, 2002 ; Accepted July 17, 2002
}

\begin{abstract}
The formation of the double hydroxide and its electrolytic reduction at the cathode in zinc-nickel alloy deposition were investigated. By using an EQCM method combined with the electrochemical measurement, it was clarified that the hydrogen generation occurs prior to the alloy deposition and the double hydroxide adheres to the electrode surface. It was confirmed that the electrolytic reduction product of the adhered material on the quartz surface was the zinc/nickel alloy with a $\mathrm{Zn}:$ Ni ratio of about $9: 1$, from the analysis by using SEM/EDX. The double hydroxide adsorbed on the cathode surface probably acts as a precursor of the alloy deposition reaction.
\end{abstract}

Key Words : Alloy Deposition, Double Hydroxide, EQCM

\section{Introduction}

In the plating of the alloy including iron group metals and zinc, an electrochemically less noble metal may mainly deposit in comparison with a noble metal. This behavior was named anomalous codeposition by Brenner. ${ }^{1 !}$

Dahms and Croll explained the anomalous codeposition by the presence of a hydroxide film on a cathode. ${ }^{2}$ This behavior was explained as follows;

(1) The $\mathrm{pH}$ value in the vicinity of a cathode rises according to the proton consumption by a cathodic reaction, for example, hydrogen evolution.

(2) Hydroxide of a less noble metal adheres to the cathode surface.

(3) The adhered hydroxide on the cathode inhibits the deposition of a noble metal.

More recently, this behavior has been explained by competitive adsorption of reaction intermediates. Tobias et $a{ }^{3} .^{3)}$ and Talbot ${ }^{4}$ et al. have suggested that the anomalous codeposition of nickel and iron occurs by the charge transfer of the monohydroxide species.

As appeared in many studies concerning the anomalous codeposition of alloys, ${ }^{3-8}$ the presence of the hydroxide during the alloy deposition processes is a key point of the reaction mechanisms. However, the role of a metal hydroxide is not clear still now. We have found that there was a common feature between the addition of alkali in a solution containing metal ion and $\mathrm{pH}$ rise near a cathode by hydrogen evolution during the plating. The formation of the hydroxide with adding alkali solution to plating solution for zinc-nickel alloy plating was examined. ${ }^{9)}$ It has been clarified that the hydroxide generated with increased $\mathrm{pH}$ was not zinc hydroxide but double hydroxide of zinc and nickel, by an analysis of the potentiometric titration, composition analysis and X-ray diffraction measurement of the product. It was confirmed that a zinc-nickel alloy can be obtained by the electrolytic reduction of the double hydroxide particles dispersed in the solution without metal ion. From these results, it is considered that the double hydroxide generated by the $\mathrm{pH}$ rise in the electrolyte can be a precursor of the alloy plating reaction.

The purpose of this paper is to investigate the formation of the double hydroxide and its electrolytic reduction at the cathode in zinc-nickel alloy deposition. Experimental results examined by using an EQCM method combined with an electrochemical measurement are reported.

\section{Experimental Method}

2. 1 Cyclic voltammetry and mass change measurement by an EQCM

The schematic diagram of the experimental equipment is shown in Fig. 1. The composition of the test solution is shown in Table 1. All solutions were prepared with reagent grade chemicals and distilled water. The $\mathrm{pH}$ of the solutions was adjusted with sulfuric acid. A gold layer on electrochemical quartz crystal (Hokuto Denko Co. Ltd.) was used as a working electrode (AT cut of $10 \mathrm{MHz}$ resonance frequency, $0.125 \mathrm{~cm}^{2}$ or AT cut of $6 \mathrm{MHz}, 0.5$ $\left.\mathrm{cm}^{2}\right)$. The $\mathrm{Ag} / \mathrm{AgCl}$ electrode was used as a reference electrode. All the potentials given below are with respect to the $\mathrm{Ag} / \mathrm{AgCl}$ reference electrode. Platinum plate of 2

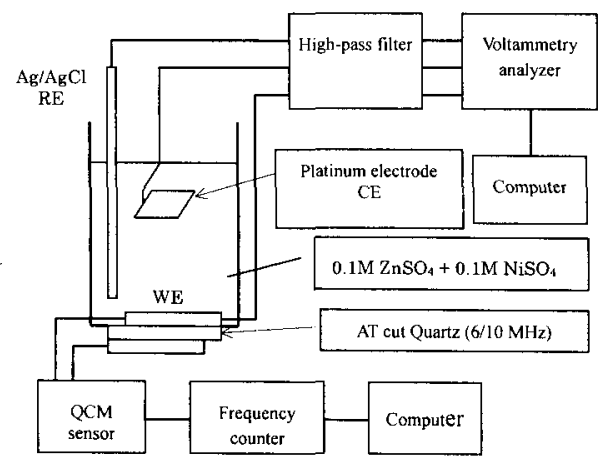

Fig. 1 Schematic diagram of voltammetry and EQCM. 
Table 1 Composition and condition of the test solution.

\begin{tabular}{lc}
\hline $\mathrm{NiSO}_{4} \cdot 6 \mathrm{H}_{2} \mathrm{O}$ & $0.1 \mathrm{~mol} \mathrm{dm}^{-3}$ \\
$\mathrm{ZnSO}_{4} \cdot 7 \mathrm{H}_{2} \mathrm{O}$ & $0.1 \mathrm{~mol} \mathrm{dm}^{-3}$ \\
\hline pH (adjusted by $\mathrm{H}_{2} \mathrm{SO}_{4}$ ) & $1.5-5.0$ \\
Bath temperature & $25^{\circ} \mathrm{C}$
\end{tabular}

$\mathrm{cm}^{2}$ was used as a counter electrode. The reference electrode and test solution were connected by the use of a salt bridge $\left(0.01 \mathrm{~mol} \mathrm{dm}^{-3} \mathrm{~K}_{2} \mathrm{SO}_{4}\right.$ agar bridge). Cyclic voltammetry was performed by using a voltammetry analyzer (CV-50 W, BAS Co., Ltd.). The initial potential was set to $-200 \mathrm{mV}$ then scanned to $-1300 \mathrm{mV}$ and reversed to $-200 \mathrm{mV}$ at the scan rate of $10 \mathrm{mV} \mathrm{s}^{-1}$. The resonant frequency change of the quartz crystal was measured by using a frequency counter (TR5822, Advantest Corp.). The relationship between the resonant frequency shift of the quartz crystal and the mass change can be described by Sauerbrey's law. ${ }^{10)}$

The frequency change per unit time is proportional to the rate of the mass change. In the case of an electrochemical reaction accompanied by mass change, such as electrodeposition of metal, a frequency change per unit time is correspondent to electrolytic current. In some cases, electrolytic current can be independent of mass change rate. Therefore, the type of reaction at an electrode surface can be judged by coincidence/inconsistency between the mass change rate and electrolytic current.

2. 2 Adsorption of the double hydroxide to EQCM surface and the electrochemical reduction of the adhered double hydroxide

The AT cut quartz crystal was soaked in the test solution, and it was kept at $-400 \mathrm{mV}$ for 1 hour, and the double hydroxide was adhered to the surface of the quartz crystal. The quartz crystal was removed from the test solution, and a residue on the quart $z$ crystal surface was flushed with $0.1 \mathrm{~mol} \mathrm{dm}^{-3} \mathrm{~K}_{2} \mathrm{SO}_{4}$ solution $(\mathrm{pH}=9)$. This quartz crystal was immersed in an electrolyte solution containing no metal ion $\left(0.1 \mathrm{~mol} \mathrm{dm}^{-3} \mathrm{~K}_{2} \mathrm{SO}_{4}(\mathrm{pH}=\right.$ 9)), and it was kept at $-1300 \mathrm{mV}$. The resonant frequency change in retaining at the fixed potential was measured, and the mass change during the electrolysis was estimated. After the constant potential electrolysis at $-1300 \mathrm{mV}$, the quartz crystal was removed from the cell, rinsed with distilled water, and dried. The surface of the quartz crystal was examined by the use of SEM/EDX, and the composition of the deposited alloy was analyzed.

\section{Results and Discussion}

\section{1 Cyclic voltammetry and mass change measured} by an EQCM

Figure 2 shows the cyclic voltammogram and the EQCM response (mass change characteristics) in 0.1 mol $\mathrm{dm}^{-3} \mathrm{ZnSO}_{4}+0.1 \mathrm{~mol} \mathrm{dm}^{-3} \mathrm{NiSO}_{4}$ solution $(\mathrm{pH}=$ 4.5) with the scanning rate of $10 \mathrm{mV} \mathrm{s}^{-1}$. The EQCM data are plotted as frequency shift per unit time, which corresponds to the mass change rate.

During a cathodic scanning process, mass increase was observed at about $-300 \mathrm{mV}$. The mass increase rate

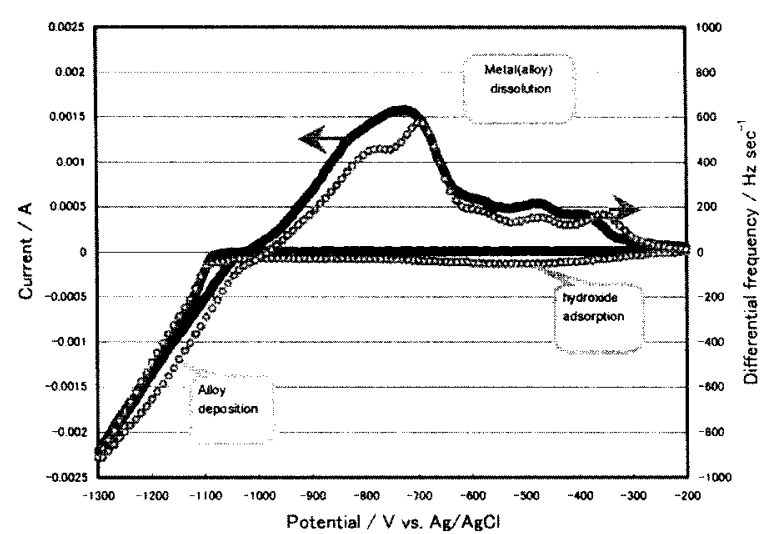

Fig. 2 Cyclic voltammogram and the EQCM response in 0.1 mol $\mathrm{dm}^{-3} \mathrm{ZnSO}_{4}+0.1 \mathrm{~mol} \mathrm{dm} \mathrm{dm}^{-3} \mathrm{NiSO}_{4}$ solution $(\mathrm{pH}=4.5)$. Potential scanning rate: $10 \mathrm{mV} \mathrm{s}^{-1}$. WE: AT cut quartz of 10 $\mathrm{MHz}, 0.125 \mathrm{~cm}^{2}$.

became a maximum at about $-400 \mathrm{mV}$, then decreased. During the potential range from $-200 \mathrm{mV}$ to $-1000 \mathrm{mV}$, the cathodic current was found to be very small (below $10 \mu \mathrm{A})$. Assuming that the quantity of the electricity passed was used only for the alloy deposition, the mass change in this potential range can be calculated. The value of this mass change was found to be $0.1 \%$ or less of the mass calculated from the frequency change of the quartz crystal. Therefore, it is considered that the mass increase in this potential range is not caused by electrochemical reaction only. This mass increase is mainly attributed to the adsorption of the double hydroxide to the cathode. Under these conditions, the $\mathrm{pH}$ value near the cathode seem to rise due to the proton consumption. Therefore, the hydroxide of metal ion may be produced in the vicinity of the electrode.

The cathodic current gradually increased from -1050 $\mathrm{mV}$, and the rate of the mass increase of the electrode was also getting larger again. These results may be originated from the mass increase by the deposition of the zinc/nickel alloy at the cathode surface. The scanning direction of the potential was inverted at $-1300 \mathrm{mV}$. Several anodic current peaks or shoulders were observed on the voltammogram. They are originated from the dissolution of the deposits formed during cathodic scanning. Several peaks or shoulders were also observed for the mass change characteristic. Five peaks or shoulders for both the anodic current and mass decrease appeared at the potentials from $-850 \mathrm{mV}$ to $-300 \mathrm{mV}$. The positions of these peaks or shoulders were almost identical for both the cyclic voltammogram and mass change characteristic. They are attributed to the dissolution reactions of five different kinds of alloys or their components. Judging from these results, it is implied that these alloys seemd to deposit in the cathodic potentials below -1100 $\mathrm{mV}$.

From the above results, the alloys seemed to deposit according to the process shown in the following scheme. First, $\mathrm{pH}$ in the vicinity of the cathode surface increased by the hydrogen generation, followed by the formation of the double hydroxide adsorbed to the cathode surface. Finally, $\mathrm{Zn}-\mathrm{Ni}$ alloy was deposited by the reduction of the adsorbed double hydroxide on the cathode. 


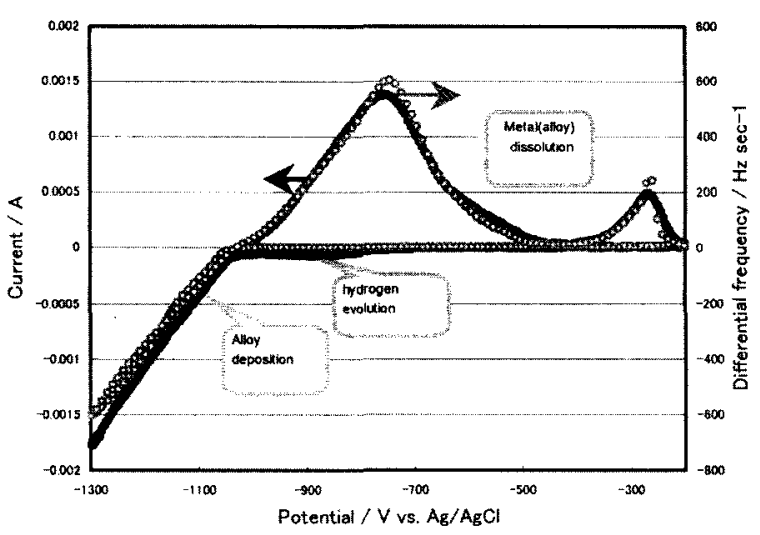

Fig. 3 Cyclic voltammogram and the EQCM response in 0.1 mol dm ${ }^{-3} \mathrm{ZnSO}_{4}+0.1 \mathrm{~mol} \mathrm{\textrm {dm } ^ { - 3 }} \mathrm{NiSO}_{4}$ solution $(\mathrm{pH}=2.7)$. Potential scanning rate: $10 \mathrm{mV} \mathrm{s}^{-1}$. WE: AT cut quartz of 10 $\mathrm{MHz}, 0.125 \mathrm{~cm}^{2}$.

Figure 3 shows the results obtained from $0.1 \mathrm{~mol}$ $\mathrm{dm}^{-3} \mathrm{ZnSO}_{4}+0.1 \mathrm{~mol} \mathrm{dm}{ }^{-3} \mathrm{NiSO}_{4}$ solution $(\mathrm{pH}=2.7)$. During the cathodic scanning, the cathodic current began to flow at about $-800 \mathrm{mV}$, whereas the mass change was not detected in the EQCM. Therefore, it seems that a reaction which is not accompanied by the adhesion to the cathode proceeds in this potential range. Below the potential of $-1100 \mathrm{mV}$, the mass increase rate was well accordant with the cathodic current. These results indicate that the alloy deposition proceeds in this potential range. The possibility of other alloy deposition mechanism can not be denied under this condition, since the hydroxide adhesion to the cathode was not detected at $\mathrm{pH}=2.7$. When the direction of the scanning potential was inverted at $-1300 \mathrm{mV}$, the anodic current derived from the dissolution of the deposits was detected, as the case of Fig. 2. Two peaks of anodic current were observed in the voltammogram. It seems that products during the cathodic scanning were different from those observed in the same solution of $\mathrm{pH}=4.5$.

Figure 4 shows the results obtained from $0.1 \mathrm{~mol}$ $\mathrm{dm}^{-3} \mathrm{ZnSO}_{4}+0.1 \mathrm{~mol} \mathrm{dm}^{-3} \mathrm{NiSO}_{4}$ solution $(\mathrm{pH}=1.5)$. In the cathodic scanning potentials, the current was found to start at about $-700 \mathrm{mV}$, and a current peak was observed at about $-950 \mathrm{mV}$. Under these conditions, the mass change of the cathode was not observed in this po-

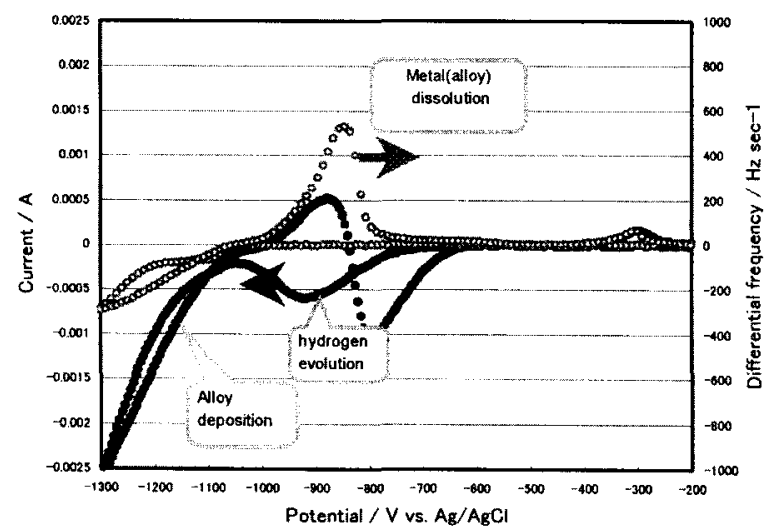

Fig. 4 Cyclic voltammogram and the EQCM response in 0.1 mol dm ${ }^{-3} \mathrm{ZnSO}_{4}+0.1 \mathrm{~mol} \mathrm{\textrm {dm } ^ { - 3 }} \mathrm{NiSO}_{4}$ solution $(\mathrm{pH}=1.5)$. Potential scanning rate: $10 \mathrm{mV} \mathrm{s}^{-1}$. WE: AT cut quartz of 10 $\mathrm{MHz}, 0.125 \mathrm{~cm}^{2}$. tential range. Therefore, a reaction which is not accompanied by the adhesion to the cathode may proceed in the same way as the cases of $\mathrm{pH}=2.7$. The behavior below $-1100 \mathrm{mV}$ is almost similar to the case of $\mathrm{pH}=2.7$, where the alloy deposition is proceeding. The scanning direction was inverted at $-1300 \mathrm{mV}$. The mass began to decrease at about $-1000 \mathrm{mV}$ and the anodic current began to flow. This behavior is due to the dissolution of the alloy or its component.

In the voltammogram, the anodic current was inverted to cathodic at about $-800 \mathrm{mV}$, whereas the mass change was found to be very small in the EQCM. This cathodic current seems to be attributed to the hydrogen formation. A peak of the anodic current was observed at about $-300 \mathrm{mV}$, and the peak for the mass decrease was also observed at the same potential. From these results, the metal or alloy seems to dissolve in this potential.

3. 2 Adsorption of the double hydroxide to EQCM surface and the electrochemical reduction of the double hydroxide

The following experiment was carried out in order to confirm whether the alloy is obtained by the electrolytic reduction of the double hydroxides.

$6 \mathrm{MHz}$ AT cut quartz crystal of $0.5 \mathrm{~cm}^{2}$ electrode surface was immersed in $0.1 \mathrm{~mol} \mathrm{dm}{ }^{-3} \mathrm{ZnSO}_{4}+0.1 \mathrm{~mol}$ $\mathrm{dm}^{-3} \mathrm{NiSO}_{4}$ solution $(\mathrm{pH}=5.0)$. Then it was polarized to $-400 \mathrm{mV}$ in order to confirm the adsorption of the double hydroxide to the electrode surface. The resonant frequency change of the quartz crystal during the controlled potential electrolysis is shown in Fig. 5. The adhesion of the hydroxide to the cathode surface seemed to be progressing during the electrolysis, because the mass is gradually increasing with time. After 1 hour electrolysis, AT cut quartz crystal was removed from the cell and the residue on the quartz crystal surface was flushed with the $0.1 \mathrm{~mol} \mathrm{dm}^{-3} \mathrm{~K}_{2} \mathrm{SO}_{4}$ solution $(\mathrm{pH}=9)$. Then, this quartz crystal was immersed in the electrolytic solution containing no metal ion $\left(0.1 \mathrm{~mol} \mathrm{dm}^{-3} \mathrm{~K}_{2} \mathrm{SO}_{4}(\mathrm{pH}=\right.$ $9.0)$ ), and it was kept at $-1300 \mathrm{mV}$. The time response of the resonant frequency change in the case of the reduction was shown in Fig. 6. The mass on the EQCM gradually decreased with time. This is due to the $\mathrm{OH}^{-}$

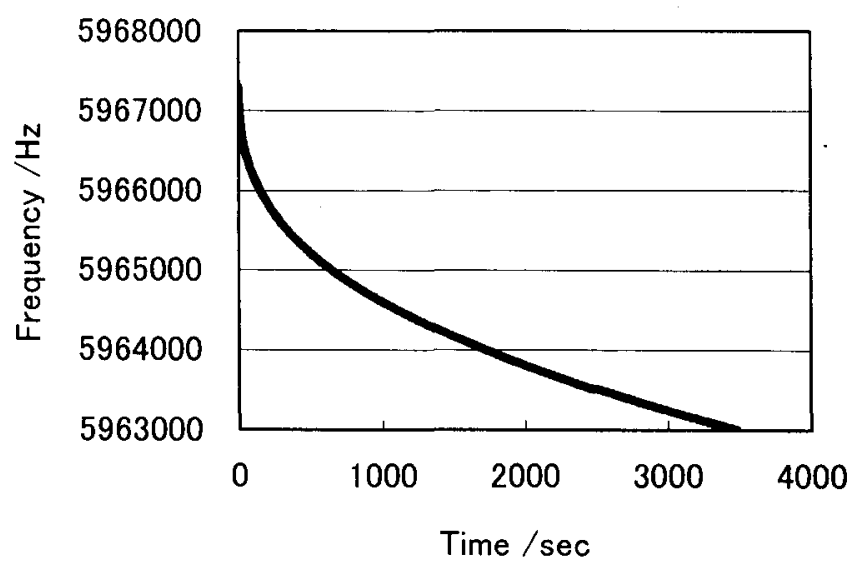

Fig. 5 Resonant frequency change of AT cut quartz during the controlled potential electrolysis. Solution: $0.1 \mathrm{~mol} \mathrm{\textrm {dm } ^ { - 3 }}$ $\mathrm{ZnSO}_{4}+0.1 \mathrm{~mol} \mathrm{dm}^{-3} \mathrm{NiSO}_{4}(\mathrm{pH}=5.0)$. Potential: $-400 \mathrm{mV}$ vs. $\mathrm{Ag} / \mathrm{AgCl}$. WE: AT cut quartz of $6 \mathrm{MHz}, 0.5 \mathrm{~cm}^{2}$. 


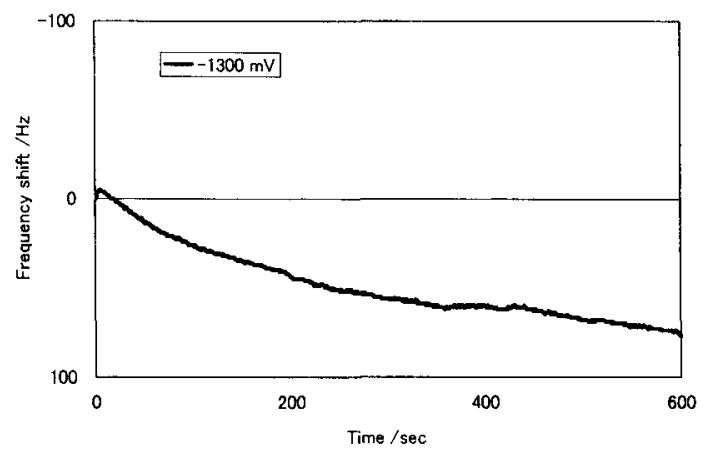

Fig. 6 Resonant frequency change of AT cut quartz during the reduction of the adhered hydroxide. Solution: $0.1 \mathrm{~mol}$ $\mathrm{dm}^{-3} \mathrm{~K}_{2} \mathrm{SO}_{4}(\mathrm{pH}=9.0)$. Potential: $-1300 \mathrm{mV}$ vs. $\mathrm{Ag} / \mathrm{AgCl}$. WE: AT cut quartz of $6 \mathrm{MHz}, 0.5 \mathrm{~cm}^{2}$.

ion desorption from the $\mathrm{EQCM}$ electrode during the electrochemical reduction of the hydroxide adsorbed to the AT cut quartz surface, for example

$$
\mathrm{M}(\mathrm{OH})_{2}+2 \mathrm{e}^{-} \longrightarrow \mathrm{M}+2 \mathrm{OH}^{-} .
$$

Quartz crystal was removed from the solution, after the electrolytic reduction. The silver gray material observed on the surface of the quartz seemed to be zinc/ nickel alloy deposit.

After cleaning and drying the quartz electrode, the surface was examined by the scanning electron microscope. The result is shown in Fig. 7, where tabular hexagonal structured deposits were observed. By the analysis of the composition of the deposit using EDX, zinc, nickel and small amount of oxygen were detected. $\mathrm{Zn}$ : Ni ratio was about $9: 1$, which well agreed with the value for the alloy obtained by conventional electroplating method. From this fact, it was confirmed that the deposits obtained by the electrolytic reduction of the adsorbed hydroxide to the cathode were zinc-nickel alloy.

From these results, it was proved that the deposit adsorbed on the cathode surface at $-400 \mathrm{mV}$ was the double hydroxide of zinc and nickel. It was confirmed that the electrochemical reduction of the double hydroxide adhered to the cathode resulted in the alloy deposit.

\section{Conclusions}

By using the quartz crystal microbalance method and the electrochemical measurement, the following results on the zinc-nickel alloy deposition were obtained:

(1) In the electrode surface, the hydrogen generation occurs prior to the alloy deposition and the double hydroxide adheres to the electrode surface.

(2) From the analysis by using SEM/EDX, it was confirmed that the electrolytic reduction product of the adhered material on the quartz surface was the zinc /nickel alloy with the $\mathrm{Zn}: \mathrm{Ni}$ ratio of about $9: 1$.

(3) In the EQCM method, the mass of the cathode decreased in the electrolytic reduction of the adsorbed materials.

From these results, it was proved that the double hydroxide on the cathode surface derived from the $\mathrm{pH}$ increase during alloy plating resulted in the alloy deposits

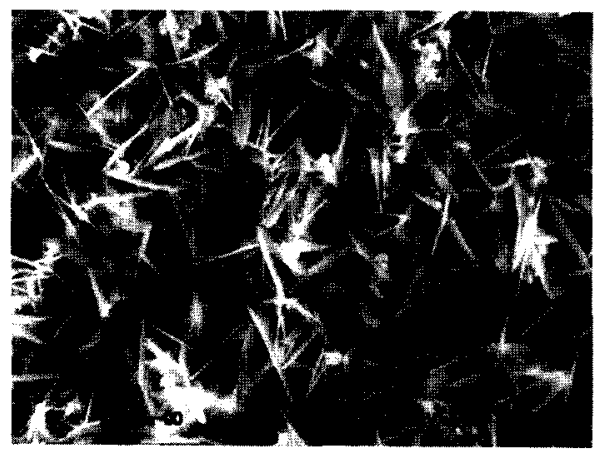

(a)

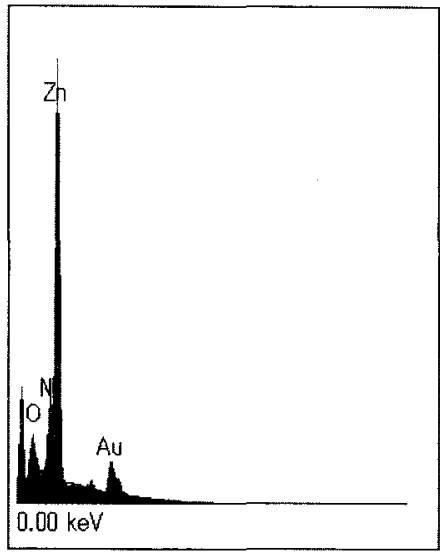

(b)

Fig. 7 SEM image (a) and EDX spectrum (b) of the reduction product from the adsorbed double hydroxide on the quartz surface.

by electrolytic reduction.

Although there is a possibility that the hydroxide formed on the cathode surface inhibits the electrodeposition of the more noble metal, it is reasonable to imply that the double hydroxide adsorbed on the cathode surface acts as a precursor of the alloy deposition reaction.

\section{References}

1) A. Brenner, Electrodeposition of Alloys, Principles and Practice, Academic Press, New York (1963).

2) H. Dahms and I. M. Croll, J. Electrochem. Soc., 112, 771 (1965).

3) S. Hessami and C. W. Tobias, J. Electrochem. Soc., 136, 3611 (1989).

4) W. C. Grande and J. B. Talbot, J. Electrochem. Soc., 140, 669 (1993).

5) N. Zech, E. J. Podlaha, and D. Landolt, J. Electrochem. Soc., 146, 2886 (1999).

6) N. Zech, E. J. Podlaha, and D. Landolt, J. Electrochem. Soc., 146, 2892 (1999).

7) K. Y. Sasaki and J. B. Talbot, J. Electrochem. Soc., 145, 981 (1998).

8) K. Y. Sasaki and J. B. Talbot, J. Electrochem. Soc., 147, 189 (2000).

9) H. Hayashi, K. Shimotsu-Goto, and I. Tari, Hyomen Gijutu, 51, 612 (2000).

10) G. Sauerbrey, Z. Phys, 155, 206 (1959). 